\title{
SERUM LACTATE ALBUMIN RATIO AS A PREDICTOR OF MORTALITY IN SEVERE SEPSIS AND SEPTIC SHOCK AT TRIBHUWAN UNIVERSITY TEACHING HOSPITAL, KATHMANDU
}

\author{
Thapa $\mathrm{S}^{1^{*}}$, Prasad $P N^{2}$, Shakya $Y M^{2}$
}

\section{Affiliation}

1. DM Emergency Medicine Resident, Department of Emergency and General Practice, Tribhuvan University Teaching Hospital, Maharajgunj, Kathmandu, Nepal

2. Professor, Head of Department, Department of Emergency and General Practice, Tribhuvan University Teaching Hospital, Maharajgunj, Kathmandu, Nepal

\section{ARTICLE INFO}

\section{Article History}

Received : 23 June, 2017

Accepted : 22 August, 2017

Published : 30 August, 2017

(c) Authors retain copyright and grant the journal right of first publication with the work simultaneously licensed under Creative Commons Attribution License CC - BY 4.0 that allows others to share the work with an acknowledgment of the work's authorship and initial publication in this journal.

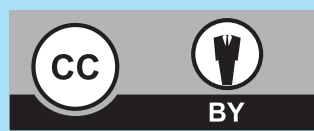

\section{ORA 29}

* Corresponding Author
Dr. Sameer Thapa
DM Emergency Medicine Resident
Department of Emergency and of General Practice
Tribhuvan University Teaching Hospital
Maharajgunj, Kathmandu, Nepal
Email: samsthp@gmail.com

\section{Citation}

Thapa S, Prasad PN, Shakya YM. Serum Lactate Albumin Ratio as a Predictor of Mortality in Severe Sepsis and Septic Shock at Tribhuwan University Teaching Hospital, Kathmandu. BJHS 2017;2 (2)3:191-195.

\section{ABSTRACT}

\section{Introduction}

Severe sepsis and septic shock, is a common cause of emergency room admission and is associated with high morbidity and mortality worldwide. This study inspects the prediction of mortality in severe sepsis and septic shock with increased lactate/albumin ratio.

\section{Objective}

The objective of the study was to predict the serum lactate albumin ratio as an indicator of mortality in severe sepsis and septic shock.

\section{Methodology}

It was a hospital based cross sectional study done at Tribhuvan University Teaching Hospital, Kathmandu from November 2015 to October 2016. The consent was taken from patients. Acute Physiology and Chronic Health Evaluation II score, serum lactate and serum albumin levels on first day of arrival in emergency room were calculated. Patients were classified as severe sepsis and septic shock and treated according to Surviving Sepsis Campaign 2012 guideline. The patient were follow up at 28 day, The associations of 28-day outcome with Acute Physiology and Chronic Health Evaluation II score, serum lactate value, serum albumin value and serum lactate albumin ratio value were derived.

\section{Results}

Out of total 240 severe sepsis and septic shock patients it is found that increased serum lactate/albumin ratio was an independent predictor of the mortality with cut off value of 0.07 . Furthermore serum lactate albumin ratio shows strong correlation with APACHE 2 score in predicting mortality in severe sepsis and septic shock.

\section{Conclusion}

Increased lactate/albumin ratio predicts mortality in patients with severe sepsis and septic shock.

\section{KEY WORDS}

Severe sepsis, septic shock, serum lactate albumin ratiow 


\section{INTRODUCTION}

Severe sepsis and septic shock, are the major cause of emergency room admission and are associated with high morbidity and mortality worldwide. ${ }^{1}$ Severe sepsis and septic shock has been recognized to have a high risk of death with high mortality rate of 20-30\% with overall hospital death of $30-50 \% .^{2-4}$ Similarly mortality rate of sepsis in Nepal found to be $40 \%$, so sepsis is still the leading cause of death., Furthermore majority of those who survives after the diagnosis of severe sepsis have poor quality of life who frequently develop cognitive and functional disability require substantial ongoing acute and long-term care. ${ }^{7-9}$ Similar to polytrauma, acute myocardial infarction or stroke, early administered resuscitation in the initial hours after severe sepsis and septic shock develops are likely to influence outcome. ${ }^{2}$ Delayed identification and inadequate resuscitation in severe sepsis and septic shock leads to the high mortality. ${ }^{10}$

As the incidences of severe sepsis and septic shock are increasing much things remains to be done to decreasing the mortality rate. ${ }^{11}$ One way to accomplish this is the early identification of severe sepsis and septic shock patients likely to die. There are lots of studies about sepsis done in developed countries but data are lacking in developing countries. ${ }^{12}$ There are currently inadequate data outlining the incidence, prevalence, predicting factors and mortality from severe sepsis and septic shock alone with bacteriological profiles, antibiotic sensitivity patterns of isolates from blood cultures in Nepal. The most important factor in decreasing mortality among severe sepsis and septic shock patients is the implementation of care bundle approaches of the Surviving Sepsis Campaign. ${ }^{13}$ If we can predict the mortality of patients with severe sepsis and septic shock in the emergency room and aggressively resuscitate them, the survival rate can be expected to increase. Authentic risk stratification tool could be used which recognizes the seriousness of the condition and assist in the best choice of early management. When there is low oxygen saturation and oxygen supply is inadequate to tissue demand anaerobic metabolism will occur, and subsequently increase in lactate production. It is established that the increased lactate is prognostic marker of generalized tissue hypoxia in distributive shock. ${ }^{14}$ There is significant increase in mortality rate in normotensive patients in the presence of systemic inflammatory response syndrome when lactate concentration is greater than $4 \mathrm{mmol} / \mathrm{I}^{15}$ Serum albumin comprises $75-80 \%$ of normal plasma colloid oncotic pressure and the degree of low serum albumin in critically ill patients directly related with the severity of infection. ${ }^{16}$ It is a negative acute phase protein and marker of outcome of severe sepsis and septic shock which decrease during the response of active phase of infections. ${ }^{17}$ Therefore, serum lactate and albumin levels which diverge during severe sepsis and septic shock merges together and provide an prognostic index that correlate positively with infection, that are inexpensive and readily available in most emergency room, with and without scoring systems.

\section{METHODOLOGY}

This was a hospital based prospective, cross sectional study approved by the institutional review board of institute of medicine tribhuvan university. The study was conducted at Department of Emergency and General Practice, Tribhuvan University Teaching Hospital (TUTH), Maharajgunj, Kathmandu Nepal, from November 2015 to October 2016. Written consent was obtained from participants. Patients with an age less than 16 years, do-not-resuscitate order, acute coronary syndrome, referred to other center, left against the medical advice, were excluded. For each patient, at emergency room conscious level, temperature, heart rate, respiratory rate, systemic blood pressure, capillary refill time, hematocrit, blood glucose level, total leukocyte counts, serum sodium, serum potassium, serum creatinine, platelets count, serum bicarbonate, Fio2, arterial $\mathrm{PH}$, serum lactate level, serum albumin alone with comorbidity like chirrosis of liver, chronic kidney disease, chronic obstructive pulmonary diseases, immune-compromised status were recorded. All patients were resuscitated according to surviving sepsis campaign 2012 guideline. $0.9 \%$ normal saline at the rate of $30 \mathrm{ml}$ per $\mathrm{kg}$ was used for fluid resuscitation for the first three hours, if mean arterial pressure (MAP) is not increased by $65 \mathrm{~mm}$ of $\mathrm{Hg}$ then inj. Noradrenalin was started within first 6 hours with target MAP of $>65 \mathrm{~mm}$ of $\mathrm{Hg}$. Acute physiological and chronic health evaluation (APACHE) II score was calculated by using APACHE II scoring system calculator -MD Calc. Serum Lactate, serum albumin and serum lactate albumin ratio was calculated within first 6 hours period. The patient were admitted in intensive care unit (ICU), medical intensive care unit (MICU), surgical intensive care unit (SICU) of TUTH after fully resuscitation in emergency room. The patient were follow up at $28^{\text {th }}$ day in terms of mortality outcome by using hospital land line phone. The associations of 28-day outcome with APACHE II score, serum lactate value, serum albumin value and serum lactate albumin ratio value is examined.

\section{RESULTS}

From Nov 2015 to Oct 2016, two hundred forty criteria fulfilled patients were included in the study. There were fiftyseven patients with severe sepsis and one hundred eighty three patients with septic shock. Out of 240 patients 53.8 percent in male group and 46.2 percent in female were expired with $p$ value of 0.128 (Table 1 ). 
Table 1: Distribution of gender among expired and improved patients $(n=240)$

\begin{tabular}{|c|c|c|c|c|c|}
\hline \multirow{2}{*}{ Sex } & \multicolumn{5}{|c|}{ Outcome } \\
\cline { 2 - 6 } & \multicolumn{2}{|c|}{ Improved } & \multicolumn{2}{c|}{ Expired } & P-value \\
\hline F & 55 & $56.7 \%$ & 66 & $46.2 \%$ & \\
\hline M & 42 & $43.3 \%$ & 77 & $53.8 \%$ & 0.128 \\
\hline Total & 97 & $100.0 \%$ & 143 & $100.0 \%$ & \\
\hline
\end{tabular}

In table 2, it was found that as there is gradually increase in serum lactate albumin ratio there is corresponding increase in mortality, when the serum lactate albumin ratio is in range of 0.01-0.20 mortality in severe sepsis and septic shock were 43.1 and $58.1 \%$ respectively.

Table 2: Association of Serum lactate albumin ratio with mortality in severe sepsis and septic shock $(n=240)$

\begin{tabular}{|r|c|c|c|c|c|c|}
\hline $\begin{array}{c}\text { Serum Lactate } \\
\text { albumin ratio }\end{array}$ & $\begin{array}{c}\text { No. of severe } \\
\text { sepsis }\end{array}$ & $\begin{array}{c}\text { Mortality } \\
\text { number(\%) }\end{array}$ & P-Value & $\begin{array}{c}\text { No. of septic } \\
\text { shock }\end{array}$ & $\begin{array}{c}\text { Mortality } \\
\text { number (\%) }\end{array}$ & P-value \\
\hline $0.01-0.20$ & 51 & $22(43.1 \%)$ & & 160 & $93(58.1 \%)$ & \\
\hline $0.21-0.40$ & 4 & $3(75.0 \%)$ & & 17 & $17(100.0 \%)$ & \\
\hline $0.41-0.60$ & 1 & $1(100.0 \%)$ & $<0.158$ & 4 & $4(100.0 \%)$ & \multirow{2}{*}{0} \\
\hline $0.61-0.80$ & 0 & 0 & & 2 & $2(100.0)$ & $<0.001$ \\
\hline$>0.81$ & 1 & $1(100.0 \%)$ & & 0 & 0 & \\
\hline Total & 57 & 27 & & 183 & 116 & \\
\hline
\end{tabular}

The age range of participants was 18 to 92 years and a mean age of 49.60 years. There is increase in mortality rate as age increases with highest mortality of $73.52 \%$ is found in age group of 58-77 years and low mortality of $46.3 \%$ in age group of $18-27$ years (Figure 1 ).

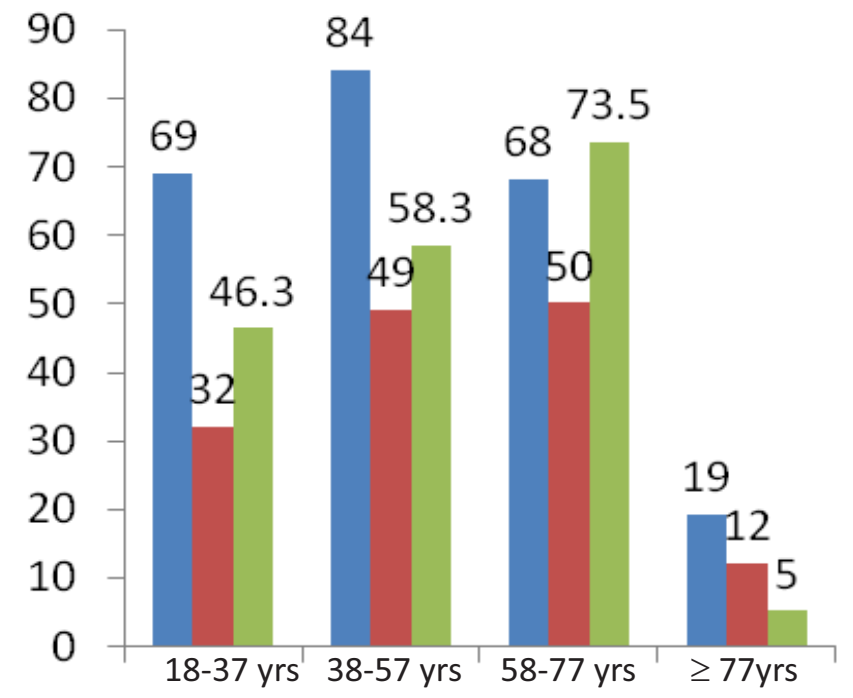

Number of Cases Mortality Number Mortality Percentage

Figure 1: Overview of patient demographics $(n=240)$

Receiver operating characteristics (ROC) curve analysis comparing serum lactate, serum lactate albumin ratio and APACHE II score in predicting mortality shows in Table 3 $(n=240$, mortality=143). The area under the ROC curve as shown in figure 2 for lactate and lactate albumin ratio were similar in predicting mortality (lactate, $0.91[95 \% \mathrm{Cl}$, $0.87-0.0 .95 ; \mathrm{p}<0.001]$ ) (lactate albumin ratio, $0.90[95 \% \mathrm{Cl}$, $0.86-0.94 ; p<0.001]$ ) where as value under the ROC curve for APACHE II score is slightly higher (APACHE II, $0.96[95 \% \mathrm{Cl}$, 0.94-0.0.98; $p<0.001])$.

Table3: Receiver operating characteristics curve (ROC) analysis between APACHE II score, serum lactate and serum lactate albumin ratio $(\mathrm{n}=\mathbf{2 4 0})$

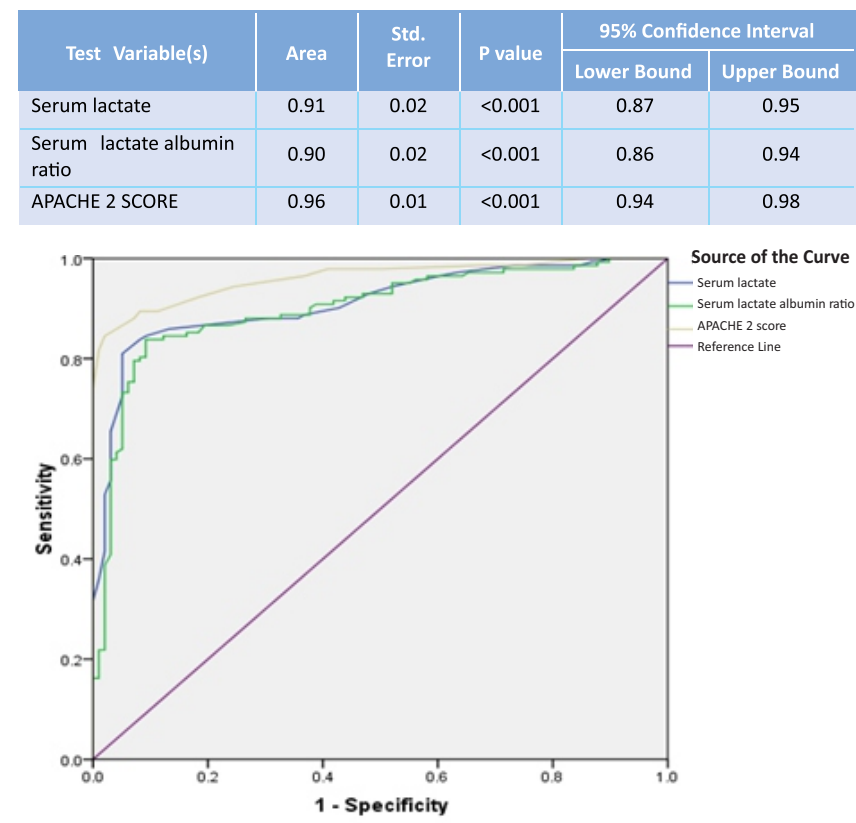

Figure 2: ROC analysis between serum lactate, serum lactate albumun ratio and APACHE II score

On correlating between APACHE II score and serum lactate albumin ratio it shows positive deflection with correlation coefficient of 0.637 and $P$ value $<0.01$ indicating that serum lactate albumin ratio shows strong correlation with APACHE II score in predicting mortality in severe sepsis and septic shock (Figure 3).

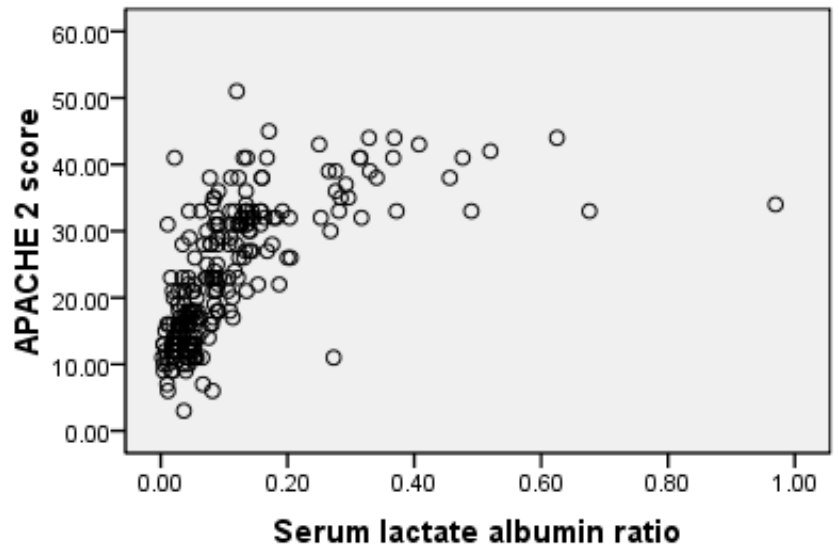

\begin{tabular}{|l|l|}
\hline Pearson Correlation & 0.637 \\
P-value & $<0.001$ \\
\hline
\end{tabular}

Figure 3: Pearson correlation between APACHE II score and serum lactate albumin ratio 


\section{DISCUSSION}

With the gradual introducing initial resuscitation methods, which decreases mortality in severe sepsis and septic shock, the focus has now moved to predicting mortality. Our study shows that in the patients with severe sepsis and septic shock lactate/albumin ratio obtained at admission in the emergency room can be used as an independent predictor of 28-day mortality. Lots of studies have been done to investigate the procalcitonin, pro-BNP, CRP to predict mortality in critically ill patients. ${ }^{18}$ But only few studies have evaluate the prognostic significance of serum lactate albumin ratio in a patient with severe sepsis and septic shock treated with end goal directed therapy.

Hypoalbuminaemia represent the inflammatory status and use in predicting outcomes in chronic and inflammatory disease. ${ }^{19,20}$ As the albumin levels are affected by both the chronic inflammatory and nutritional status this marker alone can create bias. The measurement of single lactate value in emergency room has several limitation, patient with trauma, seizure, cardiac arrest, excessive muscle activity, regional ischemia, burn and smoke inhalation, diabetic ketoacidosis, thiamine deficiency, liver dysfunction and patient under metformin all have a higher lactate. Hyperlactemia may also occur despite of hypoxia like upregulation in epinephrine-stimulated $\mathrm{Na} / \mathrm{K}$-adenosine triphosphatase activity in skeletal muscle and inhibition of pyruvate metabolism. ${ }^{21,22}$ Thus, rather than an analysis serum lactate and serum albumin, we used serum lactate /albumin ratio as a prognostic index. The combination of these two markers merged inflammatory and nutritional factors, both of which predicts prognosis. ${ }^{23}$

In our study there are total 240 patients of severe sepsis and septic shock. Out of 240 patients 57 (23.75\%) were diagnosed as severe sepsis and $183(76.25 \%)$ were diagnosed as septic shock. The patients were followed up till 28 days and mortality outcome were calculated. $28^{\text {th }}$ day mortality was $143(59.6 \%)$. It shows that in every two patient diagnosed as severe sepsis and septic shock one will die, similar results were found by study done by Christian brun et al. ${ }^{24}$ The single lactate value as a prediction of mortality in severe sepsis and septic shock is controversial as it may increase in non pathological condition for instance as a result of a high adrenaline level or alcohol intake and several studies were not able to show lactate as predictive value of mortality. ${ }^{25-28}$ APACHE II scoring system were used widely to assess out come in severe sepsis and septic shock but this is time consuming, expensive and lengthy process having multiple variables to calculate, so it is very impractical to use APACHE II scoring system in busy emergency room. So we use serum lactate albumin ratio as a marker of outcome in sepsis. It is found that as there is gradually increase in serum lactate albumin ratio there is corresponding increase in mortality. Our study findings were similar with study done by B wang et al which found that mortality in patients with severe sepsis and septic shock correlates with increased lactate/albumin ratio. ${ }^{23}$ Similar finding were also found in study done by Seung J et al. ${ }^{29}$

It is found that APACHE II score has slight higher area of 0.96 under the ROC curve in comparison with serum lactate albumin ratio, 0.90 . The reason behind is APACHE II used sum of acute physiology score, age and chronic health score with maximum score of 71 where as in lactate albumin ratio we use only two variable. So there are differences between area under the curve between APACHE II score and serum lactate albumin ratio.

However serum lactate albumin ratio shows strong correlation with APACHE 2 score in predicting mortality in severe sepsis and septic shock.

\section{CONCLUSION}

It is known that taking measurement of single lactate has several limitations. Lactate is found to be increase in numerous physiological and pathological condition as well as increased by using different types of drugs. With a cutoff value of 0.07 , this study has shows that patients with lactate/albumin ratio greater than 0.07 on day 1 had a more chance of mortality within 28 days. In the very busy emergency room where calculating APACHE 2 score is time consuming and expensive, serum lactate albumin ratio could be used as alternative marker to predict mortality in severe sepsis and septic shock.

\section{RECOMMENDATION}

Such studies could be done in multiple centre so that conclusion can be generalized. Number of the study subject could be increased to increase the power of the study.

\section{LIMITATION OF THE STUDY}

Here are several limitations to our study. First, Patients who were admitted to different unit of hospital might get different level of care which might have the effect on outcome. Second Patients with comorbid like chirrosis of liver, CKD, malnutrition were included in the study which might effect lactate albumin levels. Third all patients of severe sepsis and septic shock were generalized once they come to emergency room in spite of their level of treatment outside the hospital. In addition, this was a single-center and relatively small-sized study.

\section{ACKNOWLEDGEMENT}

I wish to express my sincere gratitude to Professor Dr. Pratap Narayan Prasad, Head, Department of Emergency and General Practice, Institute of Medicine, Kathmandu. My heartfelt gratitude goes to co-guides Prof. Dr. Yogendra Man Shakya, Department of Emergency and General and statistician Dr. Amita Pradhan.

\section{CONFLICT OF INTEREST}

We declare no conflict of interest. 


\section{REFERENCES}

1. Osborn TM, Nguyen HB, Rivers EP. Emergency medicine and the surviving sepsis campaign: an international approach to managing severe sepsis and septic shock. Annals of emergency medicine. 2005;46(3):228-31.

2. Angus DC, Linde-Zwirble WT, Lidicker J, Clermont G, Carcillo J, Pinsky MR. Epidemiology of severe sepsis in the United States: analysis of incidence, outcome, and associated costs of care. Critical care medicine. 2001;29(7):1303-10.

3. Kumar G, Kumar N, Taneja A, Kaleekal T, Tarima S, McGinley E, et al. Nationwide trends of severe sepsis in the 21st century (2000-2007). Chest Journal. 2011;140(5):1223-31.

4. Levy MM, Dellinger RP, Townsend SR, Linde-Zwirble WT, Marshall JC, Bion J, et al. The Surviving Sepsis Campaign: results of an international guideline-based performance improvement program targeting severe sepsis. Intensive care medicine. 2010;36(2):222-31.

5. Lakhey S, Karki B, Shrestha B, Shakya S, Pandey S. Sepsis: a private hospital experience in Nepal. Journal of Institute of Medicine. 2006;28(1):12-5.

6. Kaukonen K-M, Bailey M, Suzuki S, Pilcher D, Bellomo R. Mortality related to severe sepsis and septic shock among critically ill patients in Australia and New Zealand, 2000-2012. Jama. 2014;311(13):1308-16.

7. Winters BD, Eberlein $M$, Leung J, Needham DM, Pronovost PJ, Sevransky JE. Long-term mortality and quality of life in sepsis: a systematic review. Critical care medicine. 2010;38(5):1276-83.

8. Iwashyna TJ, Ely EW, Smith DM, Langa KM. Long-term cognitive impairment and functional disability among survivors of severe sepsis. Jama. 2010;304(16):1787-94.

9. Weycker D, Akhras KS, Edelsberg J, Angus DC, Oster G. Long-term mortality and medical care charges in patients with severe sepsis. Critical care medicine. 2003;31(9):2316-23.

10. Vincent J-L, Abraham E, Annane D, Bernard G, Rivers E, Van den Berghe G. Reducing mortality in sepsis: new directions. Critical Care. 2002;6(3):S1.

11. Wang HE, Shapiro NI, Angus DC, Yealy DM. National estimates of severe sepsis in United States emergency departments. Critical care medicine. 2007;35(8):1928-36.

12. Jawad I, Lukšić l, Rafnsson SB. Assessing available information on the burden of sepsis: global estimates of incidence, prevalence and mortality. population. 2012;2(3):4.

13. Angus DC, Van der Poll T. Severe sepsis and septic shock. New England Journal of Medicine. 2013;369(9):840-51.

14. Peretz DI, Scott HM, Duff J, Dossetor JB, MacLean LD, McGregor M. The significance of lacticacidemia in the shock syndrome. Annals of the New York Academy of Sciences. 1965;119(3):1133-41.

15. Aduen J, Bernstein WK, Khastgir T, Miller J, Kerzner R, Bhatiani A, et al. The use and clinical importance of a substrate-specific electrode for rapid determination of blood lactate concentrations. Jama. 1994;272(21):1678-85.
16. Al-Subaie N, Reynolds T, Myers A, Sunderland R, Rhodes A, Grounds R, et al. C-reactive protein as a predictor of outcome after discharge from the intensive care: a prospective observational study. British journal of anaesthesia. 2010;105(3):318-25.

17. Artero A, Zaragoza R, Camarena JJ, Sancho S, González R, Nogueira JM. Prognostic factors of mortality in patients with community-acquired bloodstream infection with severe sepsis and septic shock. Journal of critical care. 2010;25(2):276-81.

18. Rodelo JR, De la Rosa G, Valencia ML, Ospina S, Arango CM, Gómez Cl, et al. D-dimer is a significant prognostic factor in patients with suspected infection and sepsis. The American journal of emergency medicine. 2012;30(9):1991-9.

19. Barbosa-Silva MCG. Subjective and objective nutritional assessment methods: what do they really assess? Current Opinion in Clinical Nutrition \& Metabolic Care. 2008;11(3):248-54.

20. Qian S, Liu J. Relationship between serum albumin level and prognosis in children with sepsis, severe sepsis or septic shock. Zhonghua er ke za zhi Chinese journal of pediatrics. 2012;50(3):184-7.

21. James JH, Luchette FA, McCarter FD, Fischer JE. Lactate is an unreliable indicator of tissue hypoxia in injury or sepsis. The lancet. 1999;354(9177):505-8.

22. Curtis SE, Cain SM. Regional and Systemic Oxygen Delivery/Uptake Relations and Lactate Flux in Hyperdynamic, Endotoxin-treated 00gs14. Am Rev Respir Dis. 1992;145:348-54.

23. Wang B, Chen G, Cao Y, Xue J, Li J, Wu Y. Correlation of lactate/albumin ratio level to organ failure and mortality in severe sepsis and septic shock. Journal of critical care. 2015;30(2):271-5.

24. Brun-Buisson C, Doyon F, Carlet J, Dellamonica P, Gouin F, Lepoutre A, et al. Incidence, risk factors, and outcome of severe sepsis and septic shock in adults: a multicenter prospective study in intensive care units. Jama. 1995;274(12):968-74.

25. Luchette FA, Jenkins WA, Friend LA, Su C, Fischer JE, James JH. Hypoxia is not the sole cause of lactate production during shock. Journal of Trauma and Acute Care Surgery. 2002;52(3):415-9.

26. Dunne JR, Tracy JK, Scalea TM, Napolitano LM. Lactate and base deficit in trauma: does alcohol or drug use impair their predictive accuracy? Journal of Trauma and Acute Care Surgery. 2005;58(5):959-66.

27. Arnold RC, Shapiro NI, Jones AE, Schorr C, Pope J, Casner E, et al. Multicenter study of early lactate clearance as a determinant of survival in patients with presumed sepsis. Shock. 2009;32(1):35-9.

28. Kaplan LJ, Kellum JA. Comparison of acid-base models for prediction of hospital mortality after trauma. Shock. 2008;29(6):662-6.

29. Choi S, Ha E, Jhang W, Park S. Association between the lactate/albumin ratio and mortality in pediatric septic shock patients with underlying chronic disease: retrospective pilot study. Minerva pediatrica. 2016. 